\title{
Morphology and Properties of Poly(Lactic Acid) and Ethylene-Methyl Acrylate Copolymer Blends with Organoclay
}

\author{
Sirirat Wacharawichanant ${ }^{1, a}$, Sirinan Ratchawong ${ }^{1}$, Phakjira Hoysang ${ }^{1}$ and Manop Phankokkruad ${ }^{2}$ \\ ${ }^{1}$ Department of Chemical Engineering, Faculty of Engineering and Industrial Technology, Silpakorn University, Nakhon Pathom 73000, \\ Thailand \\ ${ }^{2}$ Faculty of Information Technology, King Mongkut's Institute of Technology Ladkrabang, Bangkok 10520, Thailand
}

\begin{abstract}
The effects of nanoclay with surface modified by $25-30 \mathrm{wt} \%$ of octadecylamine (Clay-ODA) on mechanical, thermal and morphological properties of poly(lactic acid) (PLA)/ethylene-methyl acrylate copolymer (EMAC) blends with various Clay-ODA contents were investigated. The EMAC with $19.60 \mathrm{wt} \%$ of methyl acrylate (or EMAC1820) was used, and the ratio of PLA and EMAC1820 was $80 / 20$ by weight, and the Clay-ODA contents were 1, 3, 5 and $7 \mathrm{phr}$. The morphology analysis showed that the addition of Clay-ODA could improve the miscibility of PLA/EMAC1820 blends due to the decrease the domain sizes of dispersed EMAC1820 phase in the PLA matrix. The mechanical properties showed Young's modulus, stress at break and storage modulus of PLA/EMAC1820 blends was improved after adding Clay-ODA. The addition of Clay-ODA did not effect on the melting temperature and glass transition temperature of PLA and PLA blends. The thermal stability of PLA could improve by adding EMAC1820 and Clay-ODA.
\end{abstract}

\section{Introduction}

Poly(lactic acid) (PLA) is biodegradable polymer and a linear aliphatic thermoplastic polyester, which can be synthesized by condensation of lactic acid or ring opening polymerization of lactide [1-2]. PLA can processes similarly to polyolefins by conventional processing methods such as extrusion, tubular blown film, injection molding, and thermoforming and PLA has high strength, high modulus and transparency [3]. However, the main weak points of PLA properties are too brittle for many applications, low heat distortion temperature (HDT) and low thermal stability compared to commercial polymers [4-7]. To more applications of PLA need to improve the mechanical and thermal properties by blending with the flexible and toughness materials.

Some literatures have studied to improve the mechanical, thermal and barrier properties, and degradation behavior of PLA by blending with rubber, plasticizers, thermoplastic starch (TPS) and other thermoplastic polymers [8-12]. For instance, Juntuek et al. [8] studied the properties of PLA/natural rubber (NR) blends at various ratios using an internal mixer. The impact strength and elongation at break of PLA/NR blends dramatically increased with increasing NR content up to $10 \%(\mathrm{w} / \mathrm{w})$. Glycidyl methacrylate-grafted natural rubber (NR-g-GMA) was used as a compatibilizer for PLA/NR blends. The results showed that the addition of NR-g-GMA in PLA/NR blends significantly improved impact strength and elongation at break of PLA/NR

\footnotetext{
a Corresponding author: sirirat.che@gmail.com
}

blends when compared with that of neat PLA and PLA/NR blends without NR-g-GMA. Thermal property results indicated NR had higher thermal stability than PLA. The increase of thermal stability of PLA due to the good interaction between the blend components was reported in other PLA blends and composites. In the same way, Tanrattanakul and Bunkaew [9] prepared NR/PLA $(60 / 40)$ blends by melt blending in an internal mixer and investigated the effect of plasticization of PLA on the mechanical and physical properties of the derived NR/PLA. Four plasticizers were used: tributyl acetyl citrate (TBAC), tributyl citrate (TBC), glycerol triacetate (GTA), and triethyl-2-acetyl citrate (TEAC). They reported that all plasticizers increased the strain at break. The presence of $4 \mathrm{phr}$ of plasticizer provided the highest strength and tensile toughness, and the strain at break increased with the increasing plasticizer content.

Ferrarezi et al. [10] prepared PLA/TPS blends by using poly(ethylene glycol) (PEG), a non-toxic polymer, as a compatibilizer. They found that PLA/TPS blends presented large TPS phase size distribution and low adhesion between phases, which was responsible for the lower elastic modulus of this blend when compared to pure PLA. The addition of PEG resulted in the increase of PLA crystallization, due to its plasticizing effect, and improvement of the interfacial interaction between TPS and PLA matrix. The incorporation of PEG increased the impact strength of the ternary blend and that the elastic modulus remained similar to the PLA/TPS blends. Furthermore, Bee et al. [11] studied the properties of 
PLA and low density polyethylene (LDPE) blends. They reported that the tensile strength and Young's modulus of the PLA/LDPE blends reduced with an increasing percentage of LDPE due to the lower intermolecular bonding of LDPE than of PLA. Thus, they used the electron beam irradiation to improve PLA/LDPE properties. The result showed the increasing irradiation dosage enhanced the mechanical properties of PLA/LDPE blends at higher LDPE content.

From some researchers have studied using the rubber and flexible polymer to improve the mechanical properties of PLA, and using organoclay to improve the miscibility and properties of PLA blends for more applications. In stance, Hasook et al. [13] studied the mechanical properties of PLA/poly( $\varepsilon$-caprolactone) (PCL)/organoclay nanocomposites. They reported that Young's modulus of PLA/organoclay nanocomposite was more than that of neat PLA. The tensile strength of the PLA/PCL (molecular weight $10 \mathrm{~K}$ and $40 \mathrm{~K}$ )/organoclay nanocomposites was higher than that of neat PLA, and the elongation of the PLA/PCL/organoclay composites also improved. Moreover, the thermal stability of the PLA/organoclay nanocomposite increased with the addition of PCL. Bijarimi et al. [14] investigated the mechanical, thermal and morphological properties of PLA/liquid natural rubber/Cloisite C30B (C30B) nanocomposites. The results found that Young's modulus and flexural modulus increased with the addition of $\mathrm{C} 30 \mathrm{~B}$ to the PLA/liquid natural rubber blends. The elongation at break of PLA/liquid natural rubber increased significantly as compared to nanocomposite with $1 \%$ of C30B. Nevertheless, the elongation at break and impact strength decreased gradually when nanoclay content increased above $3 \%$. This study indicated that PLA/liquid natural rubber-toughened nanocomposites with a higher modulus and that thermal stability could be produced.

From above the literature review showed that the organoclay can improve the mechanical properties of PLA blends, Thus, this work studied the influence of Clay-ODA on morphology and mechanical properties of PLA/EMAC1820 blends. The blends and composites with varying concentration of Clay-ODA were prepared by a melt mixing technique in an internal mixer, and the sample was molded by compression molding.

\section{Experimental}

\subsection{Materials}

PLA with the melt flow index $\left(210^{\circ} \mathrm{C} / 2.16 \mathrm{~kg}\right)$ of 6.0 $\mathrm{g} / 10 \mathrm{~min}$ and specific gravity of 1.24 was produced by NatureWorks LLC, USA, under the trade name of "Ingeo ${ }^{\mathrm{TM}}$ Biopolymer 2003D". The ethylene-methyl acrylate copolymer (EMAC) has the melt flow index $\left(190^{\circ} \mathrm{C} / 2.16 \mathrm{~kg}\right)$ of $3.95 \mathrm{~g} / 10 \mathrm{~min}$ and density of 0.926 $\mathrm{g} / \mathrm{cm} 3$, and EMAC was produced by DuPont Company. EMAC with $19.60 \mathrm{wt} \%$ of methyl acrylate was called EMAC1820. The nanoclay surface modified with 25-30 $\mathrm{wt} \%$ of octadecylamine (Clay-ODA) was purchased from Aldrich Company.

\subsection{Sample Preparation}

Before blending, PLA was dried in an oven at $80^{\circ} \mathrm{C}$ for 4 $\mathrm{h}$, and Clay-ODA was dried at $80^{\circ} \mathrm{C} 24 \mathrm{~h}$. EMAC1820 was not dried before blending process. PLA/EMAC1820 ( $80 / 20$ by weight) were prepared by melt blending in an internal mixer at $180^{\circ} \mathrm{C}$ and a rotor speed of $80 \mathrm{rpm}$ for 15 min. PLA/EMAC1820 (80/20 by weight) with ClayODA contents 1, 3, 5 and $7 \mathrm{phr}$ was prepared in a same condition, and Clay-ODA was added after $5 \mathrm{~min}$ of mixing. After compounding, polymer blends without and with Clay-ODA were dried in an oven at $80^{\circ} \mathrm{C}$ for $1 \mathrm{~h}$ for reject moisture. Afterward, the blends and composites were compression molded at $180^{\circ} \mathrm{C}$ for $15 \mathrm{~min}$ for impact and tensile tests. DMA samples were prepared by compression molding at $180^{\circ} \mathrm{C}$ for $12 \mathrm{~min}$. TGA samples were prepared as a film by compression molding at $180^{\circ} \mathrm{C}$ for $5 \mathrm{~min}$.

\subsection{Sample Characterization}

The morphology of impact fractured surfaces of PLA/EMAC1820 blends without and with Clay-ODA was investigated by scanning electron microscope (SEM) instruments (Maxim 2000S, CamScan Analytical) at 15 $\mathrm{kV}$ accelerating voltage after gold coating.

The impact strength of PLA/EMAC1820 blends without and with Clay-ODA was measured using a noted Izod impact tester (Zwick/material testing AugustNagelstr.11.D-89079 Ulm) at room temperature. The impact test was performed according to ASTM D 256. Tensile test was conducted according to ASTM D 638 with a universal tensile testing machine (LR 50k from Lloyd instruments) at a crosshead speed of $50 \mathrm{~mm} / \mathrm{min}$. Each value obtained represented the average of five samples.

Dynamic mechanical analysis (DMA) for the thermomechanical properties (storage modulus) of PLA/EMAC1820 blends without and with Clay-ODA were measured in bending film mode at a constant vibration frequency of $1 \mathrm{~Hz}$, a temperature range of 30$140^{\circ} \mathrm{C}$, and a heating rate of $5^{\circ} \mathrm{C} / \mathrm{min}$ in a nitrogen atmosphere with a dynamic mechanical analyzer (Pyris Diamond DMA, Perkin Elmer).

The degradation temperature of PLA/EMAC 1820 blends without and with Clay-ODA was measured by thermogravimetric analysis (TGA) (Model SDT Q600, TA Instruments). The temperature was in the range of 30$600^{\circ} \mathrm{C}$ at a heating rate of $10^{\circ} \mathrm{C} / \mathrm{min}$ under nitrogen atmosphere.

\section{Results and Discussion}

\subsection{Morphology}

Figure 1 shows the SEM micrographs of the impact fractured surfaces of pure PLA, PLA/Clay-ODA and PLA/EMAC1820 (80/20) blends, respectively. The fractured surface of pure PLA was quite smooth which characteristic of a brittle semicrystalline polymer. The fractured surface of PLA/Clay-ODA composites was 
more roughness when compared with pure PLA. The fractured surface of PLA/EMAC1820 blends clearly demonstrated a two-phase separation of dispersed EMAC1820 phase and the PLA matrix phase. The SEM image observed the minor phase of EMAC1820 dispersed as spherical domains in PLA matrix and the microvoids surrounding the droplets of dispersed EMAC1820 phase indicated a weak interfacial adhesion in the blends. Due to the immiscible nature of the polymers, high interfacial tension between the two polymers and the spherical morphology is anticipated because of the minimization of the interfacial area [15].

Figure 2 shows the SEM micrographs of the impact fractured surfaces of PLA/EMAC1820/Clay-ODA composites. The addition of Clay-ODA in the PLA/EMAC1820 blends reduced the spherical domain sizes of dispersed EMAC1820 phase significantly when compared with the blends without Clay-ODA. The spherical domain sizes of EMAC1820 phase decreased with increasing Clay-ODA content. This indicated that Clay-ODA played an important role in reducing the spherical domains of EMAC1820 of the polymer blends and improved adhesion interaction between PLA and EMAC1820 phases.
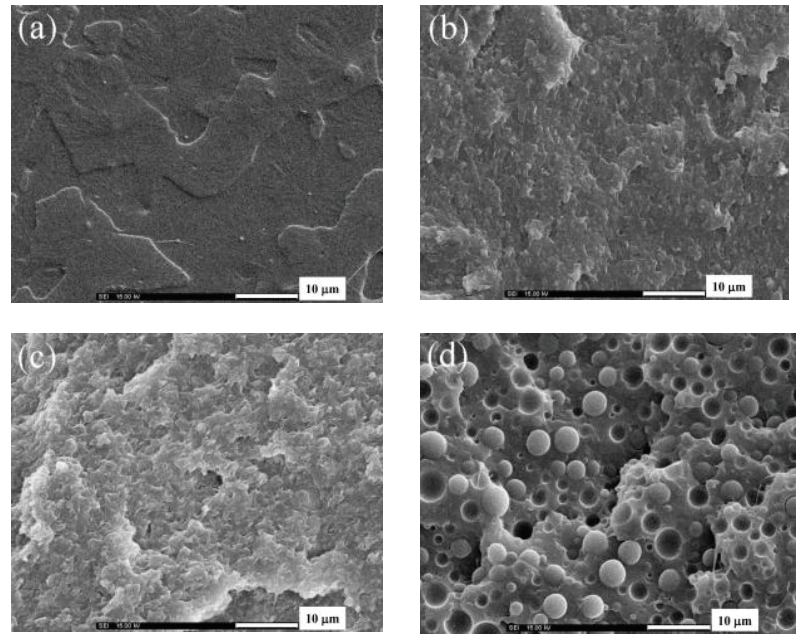

Figure 1. SEM micrographs of (a) pure PLA, (b) PLA/ClayODA (100/3), (c) PLA/Clay-ODA (100/7), and (d) PLA/EMAC1820 (80/20).

\subsection{Mechanical Properties}

Each value obtained of mechanical properties represented the average of five samples and the standard deviation displayed in error bar. Figure 3 shows the impact strength of PLA/EMAC1820/Clay-ODA composites with various Clay-ODA contents. The result found that the impact strength of PLA decreased with increasing Clay-ODA content. This implied that the addition of Clay-ODA did not improve the impact strength of PLA/EMAC blends due to the structure of Clay-ODA decreased the movement of entangled polymer chains, and as ClayODA loading increased the brittleness of the polymer composites increased.

Figure 4 shows Young's modulus of PLA/EMAC1820/Clay-ODA composites with various Clay-ODA contents. Young's modulus of PLA/EMAC1820/Clay-ODA composites increased with increasing Clay-ODA content. Young's modulus of PLA/EMAC1820/Clay-ODA composites was higher than that of PLA/EMAC1820 blends. Thus, the incorporation of Clay-ODA significant improved the Young's modulus of PLA/EMAC1820 blends due to the reinforcement effect of the rigid inorganic Clay-ODA induced a substantial increase in the modulus of the composites.
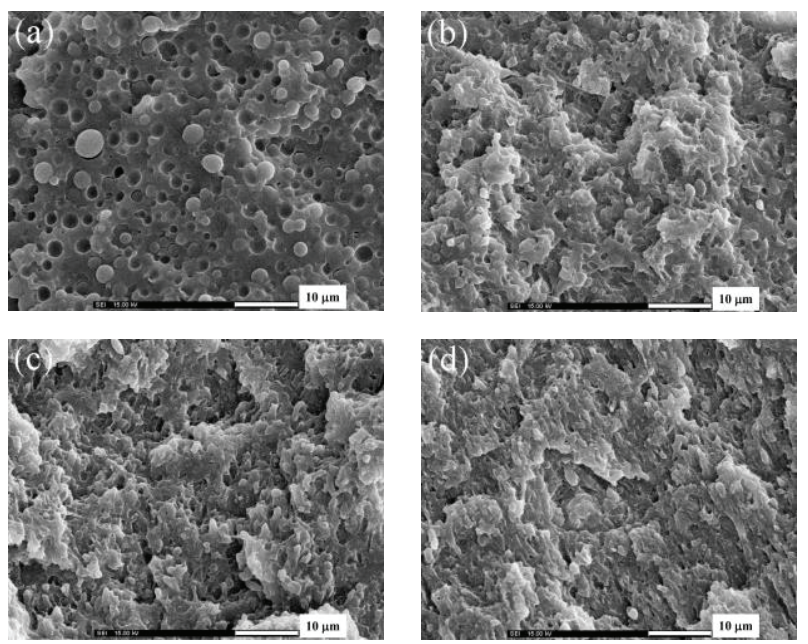

Figure 2. SEM micrographs of PLA/EMAC1820/Clay-ODA composites (a) 80/20/1, (b) 80/20/3, (c) 80/20/5, and (d) 80/20/7.

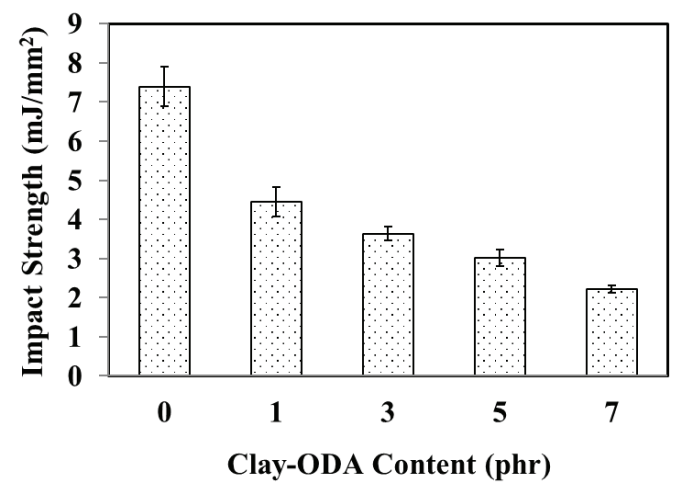

Figure 3. Impact strength of PLA/EMAC1820 blends without and with Clay-ODA.

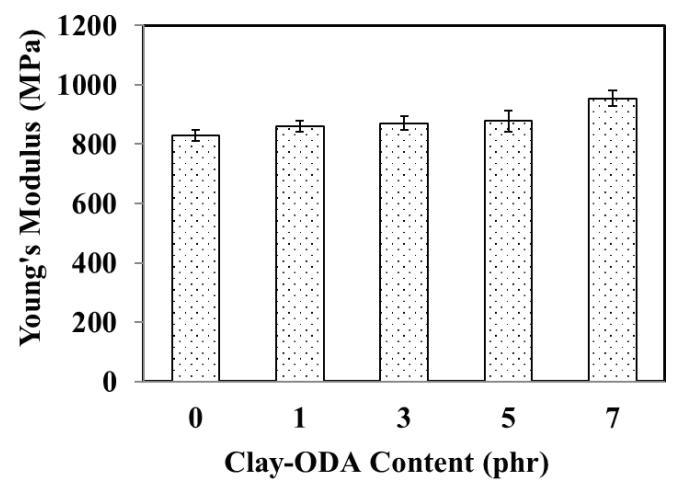

Figure 4. Young's modulus of PLA/EMAC1820 blends without and with Clay-ODA.

The tensile strength of PLA/EMAC1820 blends without and with Clay-ODA is presented in Figure 5. The tensile strength of PLA/EMAC1820 blends slightly decreased with increasing Clay-ODA content. This result 
indicated that the addition of Clay-ODA did not improve the tensile strength of PLA/EMAC1820 blends.

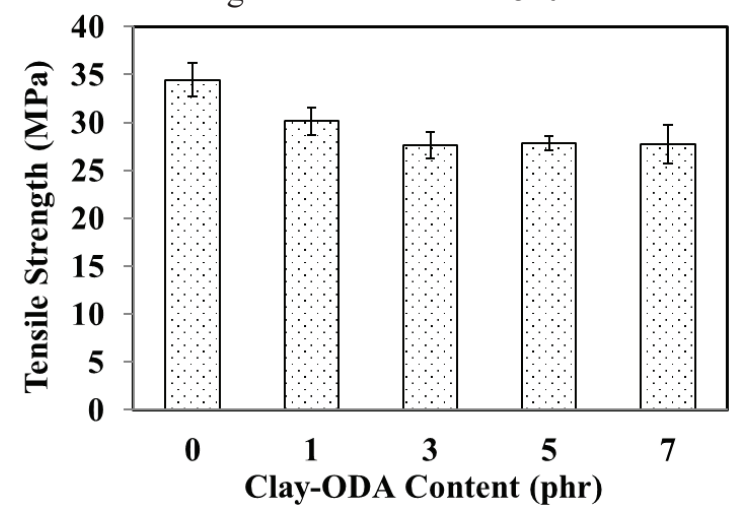

Figure 5. Tensile strength of PLA/EMAC1820 blends without and with Clay-ODA.

Figure 6 shows the stress at break of PLA/EMAC1820/Clay-ODA composites, the result found that the stress at break of PLA/EMAC1820/ClayODA composites increased at high Clay-ODA loading. The stress at break was lower than tensile strength due to the sample did not break at a yield point, but the sample could absorb the tensile stress and elongated before the breaking point. This can be explained that the addition of Clay-ODA at high content could improve the stress at break of the PLA/EMAC1820 blends due to Clay-ODA could absorb the tensile stress from the polymer matrix before the breaking point.

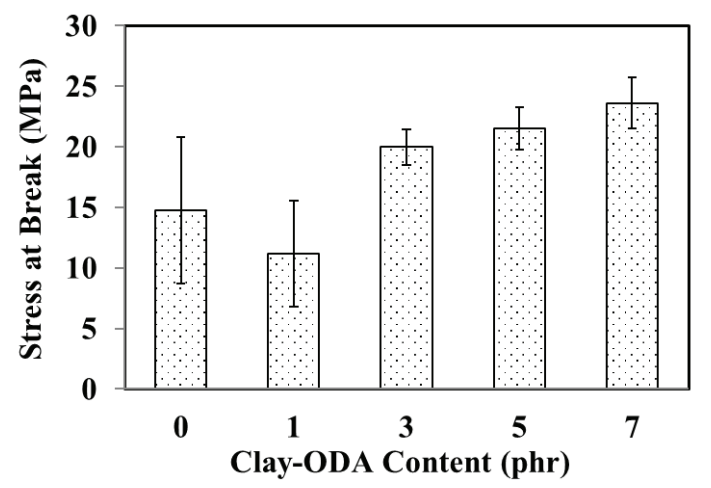

Figure 6. Stress at break of PLA/EMAC1820 blends without and with Clay-ODA.

Figure 7 shows the effect of Clay-ODA content on the strain at break of PLA/EMAC1820 blends. The result found that the strain at break of PLA/EMAC1820 blends increased when added Clay-ODA $1 \mathrm{phr}$ and $3 \mathrm{phr}$ and decreased at high Clay-ODA content. This can be explained that the layered Clay-ODA reduced the flexibility and elongation of a polymer chain after added high Clay-ODA loading.

The variation of storage modulus of PLA, PLA/EMAC1820 blends and composites is presented in Figure 8 . The storage modulus PLA/EMAC1820 blends and PLA/EMAC1820/Clay-ODA composites tended to decrease with increasing temperature. The storage modulus of pure PLA showed the highest value, and it was higher than PLA/EMAC1820 blends and composites.
Moreover, the addition of Clay-ODA could improve the storage modulus of PLA and PLA/EMAC1820 blends.

\subsection{Thermal Properties}

The results of thermal properties showed that the melting temperatures $\left(\mathrm{T}_{\mathrm{m}}\right)$ of PLA and PLA/Clay-ODA (100/3) were $151.3^{\circ} \mathrm{C}$ and $153.4^{\circ} \mathrm{C}$, while $\mathrm{T}_{\mathrm{m}}$ of blends and composites were not significantly changed when EMAC1820 and Clay-ODA was incorporated in the polymer matrix. The glass transition temperature $\left(\mathrm{T}_{\mathrm{g}}\right)$ of PLA was $66.4^{\circ} \mathrm{C}$ and the glass transition temperature of $\mathrm{PLA} / \mathrm{Clay}-\mathrm{ODA}$ composites was $67.7 \pm 0.7^{\circ} \mathrm{C}$. While the glass transition temperature of PLA blends and composites was $68.0 \pm 1.0^{\circ} \mathrm{C}$ as shown in Table 1 . Thus, the glass transition temperatures of the PLA and blends were not significantly changed when added Clay-ODA.

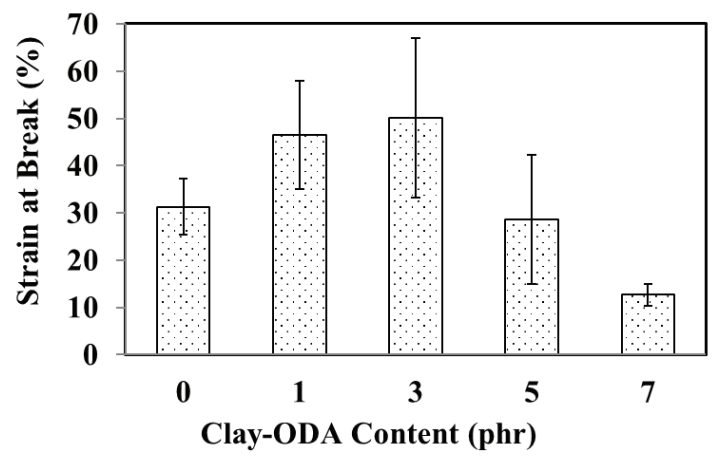

Figure 7. Strain at break of PLA/EMAC1820 blends without and with Clay-ODA.

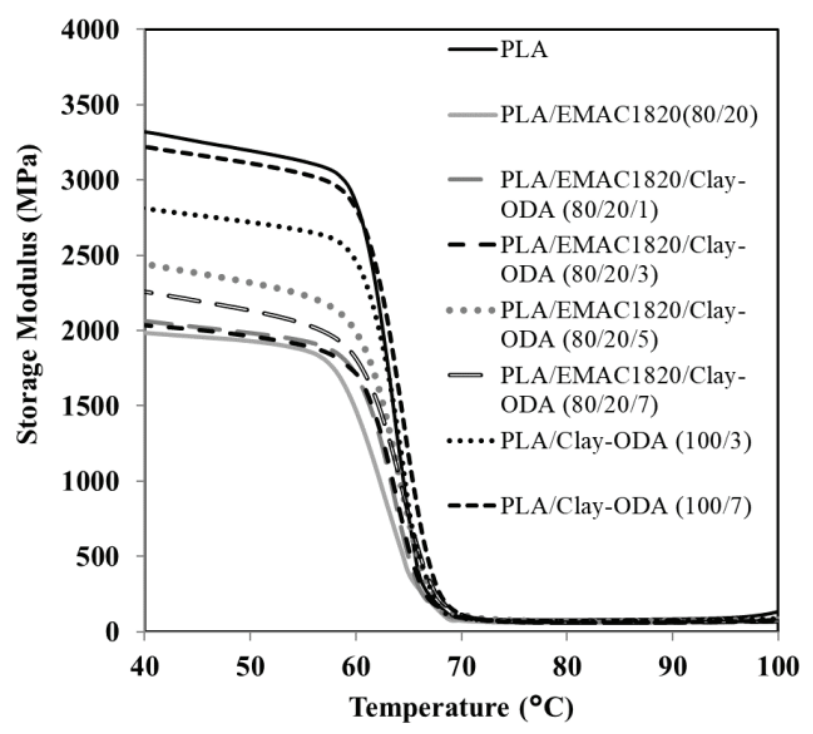

Figure 8. Storage modulus of PLA/EMAC1820 blends without and with Clay-ODA.

The degradation temperatures corresponding to the $10 \%$ weight loss $\left(\mathrm{T}_{\mathrm{d} 10}\right)$ were calculated as shown in Table 1. The degradation temperatures of PLA, EMAC1820 and Clay-ODA were $315.4,426.2$ and $358.6^{\circ} \mathrm{C}$, respectively. This indicated the thermal stability of EMAC1820 was higher than that of PLA. The result showed the incorporation of EMAC1820 and Clay-ODA 
improved the degradation temperature of PLA. This indicates that an improvement in the thermal stability in the PLA/EMAC1820 blends due to EMAC1820 and Clay-ODA had the higher degradation temperature.

Figure 9 shows the thermogravimetric curves of thermal degradation of pure PLA, EMAC1820, ClayODA and PLA/EMAC1820 blends and composites. It is evident that the thermal degradation of PLA, EMAC1820, Clay-ODA showed only single step of weight loss, while the thermal degradation of PLA/EMAC1820 blends and composites proceeded by two degradation steps. It observed that the first step showed the large mass loss of thermal degradation of PLA. The second step showed a small mass loss of thermal degradation of EMAC1820.

Table 1. $T_{m}, T_{g}$ and $T_{d 10}$ of PLA, PLA blends and composites.

\begin{tabular}{|l|c|c|c|}
\hline Sample & $\mathrm{T}_{\mathrm{m}}\left({ }^{\circ} \mathrm{C}\right)$ & $\mathrm{T}_{\mathrm{g}}\left({ }^{\circ} \mathrm{C}\right)$ & $\mathrm{T}_{\mathrm{d} 10}\left({ }^{\circ} \mathrm{C}\right)$ \\
\hline PLA & 151.3 & 66.4 & 315.4 \\
\hline EMAC1820 & - & - & 426.2 \\
\hline Clay-ODA & - & 67.2 & 338.6 \\
\hline PLA/Clay-ODA (100/1) & - & 67.8 & 331.8 \\
\hline PLA/Clay-ODA (100/3) & 153.4 & 67.1 & 336.4 \\
\hline PLA/Clay-ODA (100/5) & - & 68.7 & 335.8 \\
\hline PLA/Clay-ODA (100/7) & - & 68.6 & 343.6 \\
\hline PLA/EMAC1820 (80/20) & 154.7 & 66.6 & 343.0 \\
\hline $\begin{array}{l}\text { PLA/EMAC1820/Clay- } \\
\text { ODA (80/20/1) }\end{array}$ & - & 67.2 & 342.9 \\
\hline $\begin{array}{l}\text { PLA/EMAC1820/Clay- } \\
\text { ODA (80/20/3) }\end{array}$ & 153.1 & 68.8 & 340.0 \\
\hline $\begin{array}{l}\text { PLA/EMAC1820/Clay- } \\
\text { ODA (80/20/5) }\end{array}$ & - & 68.6 & 337.9 \\
\hline $\begin{array}{l}\text { PLA/EMAC1820/Clay- } \\
\text { ODA (80/20/7) }\end{array}$ & - & \multicolumn{3}{|l}{} \\
\hline
\end{tabular}

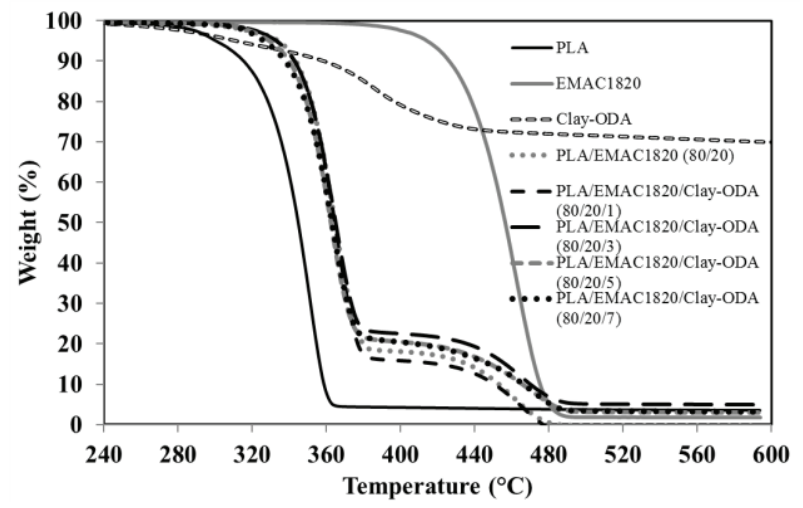

Figure 9. TGA thermograms of Clay-ODA, EMAC, PLA and PLA/EMAC1820 blends and composites.

\section{Conclusions}

The effects of Clay-ODA on mechanical, thermal and morphological properties of PLA/EMAC1820 blends with various Clay-ODA contents were investigated. The morphology analysis showed that the addition of ClayODA could improve the miscibility of PLA/EMAC1820 blends due to the decrease the domain sizes of EMAC1820 dispersed phase in the PLA matrix and improved the miscibility of blends. The mechanical properties showed that the impact strength of
PLA/EMAC1820/Clay-ODA composites decreased with increasing Clay-ODA content. While Young's modulus, stress at break and storage modulus of PLA/EMAC1820 blends was improved after adding Clay-ODA. The addition Clay-ODA did not change the melting temperature and glass transition temperature of PLA and PLA blends. The addition of EMAC1820 and Clay-ODA could improve the degradation temperature of PLA.

\section{Acknowledgements}

The authors would like to thank Silpakorn University Research and Development Institute (SURDI) for the financial support of this project.

\section{References}

1. N.I. Akos, M.U. Wahit, R. Mohamed, A.A. Yussuf, Polym. Compos. 34, 763 (2013)

2. I. Spiridon, K. Leluk, A.M. Resmerita, R.N. Darie, Composites: Part B 69, 342 (2015)

3. R. Jaratrotkamjorn, C. Khaokong, V. Tanrattanakul, J. Appl. Polym. Sci. 124, 5027 (2012)

4. K. Halász, L. Csóka, Journal of Engineering DOI: 10.1155/2013/329379: 1 (2013)

5. N.F.M. Rawi, K. Jayaraman, D. Bhattacharyya, J. Reinf. Plast. Comp. 32, 1513 (2013)

6. R. Tokoro, D.M. Vu, K. Okubo, T. Tanaka, T. Fujii, T. Fujiura, J. Mater. Sci. 43, 775 (2008)

7. S. Pilla, S. Gong, E. O'Neill, R.M. Rowell, A.M. Krzysik, Polym. Eng. Sci. 48, 578 (2008)

8. P. Juntuek, C. Ruksakulpiwat, P. Chumsamrong, Y. Ruksakulpiwat, J. Appl. Polym. Sci. 125, 745 (2012)

9. V. Tanrattanakul, P. Bunkaew, eXPRESS Polym. Lett. 8, 387 (2014)

10. M.M.F. Ferrarezi, M. de Oliveira Taipina, L.C.E. da Silva, M. do Carmo Gonçalves, J. Polym. Environ. 21, 151 (2013)

11. S.-T. Bee, C.T. Ratnam, L.T. Sin, T.-T. Tee, W.K. Wong, J.-X. Lee, A.R. Rahmat, Nucl. Instr. Meth. Phys. Res. B 334, 18 (2014)

12. J. Liu, H. Jiang, L. Chen, J. Polym. Environ. 20, $810(2012)$

13. Hasook A, Tanoue S and Iemoto Y Polym. Eng. Sci. 46, 1001 (2006)

14. M. Bijarimi, S. Ahmad, R. Rasid, J. Reinf. Plast. Comp. 32, 1656 (2013)

15. S. Wacharawichanant, P. Amorncharoen, R. Wannasirichoke, Polym. Plast. Technol. Eng. 54, 1349 (2015). 